\title{
Pengaruh Gaya Hidup Berbelanja Dan Perilaku Hedonik Terhadap Pembelian Impulsif (Studi Pada Toko Belanja Online Shopee)
}

\author{
Debora Dian Maydiana Anggreani; Sentot Suciarto A. \\ debbykwee.debora@gmail.com \\ Magister Manajemen Universitas Katolik Soegijapranata
}

\begin{abstract}
This research aimed to test the effect of shopping lifestyle and hedonic behavior toward impulsive buying. Population researched here are students consuming shopee online shopping with sampel 100 taken by purposive sampling. It was obtained test result that respon toward shopping lifestyle was agree, average score 4.18. Average respon toward hedonic behavior was agree, 3.87. Average respon toward impulsive buying was agree, namely 3.92. Based on regression analysis, shopping lifestyle positively and significantly effected impulsive buying. Hedonic behavior also effected toward impulsive buying. The test result shopping lifestyle and hedonic behavior together significantly effected toward impulsive buying.
\end{abstract}

Keywords: shopping lifestyle, hedonic behavior, impulsive buying.

\section{PENDAHULUAN}

Pembelian impulsif atau unplanned purchase adalah perilaku dimana seseorang tidak merencanakan suatu pembelian terhadap suatu barang tertentu dalam berbelanja (Cobb and Hoyer, 1986). Dalam melakukan pembelian impulsif, konsumen tidak pernah berpikir untuk membeli suatu produk atau merek tertentu. Mereka langsung melakukan pembelian dengan alasan ketertarikan akan merek atau produk pada saat itu juga.

Kebutuhan seseorang dalam memenuhi kebutuhannya semakin kompleks dan beragam, namun waktu terbatas akibat dari kesibukan yang ada. Perusahaan kini mulai menawarkan belanja dimana pembeli tidak bertemu dengan penjual secara langsung melalui aplikasi berbelanja secara online. Adanya online shop lebih memudahkan orang dalam memenuhi kebutuhan barang yang dicari. Berbelanja melalui online shop juga dirasa lebih menarik karena lebih praktis tanpa mengharuskan seseorang datang ke toko dan tanpa dibatasi oleh jam operasional toko. Pembeli dapat melakukan transaksi kapanpun dan dimanapun selagi memiliki jaringan koneksi internet (Wells et al., 2011). Pembelian impulsif di dunia nyata dapat terjadi di mall ataupun toko dimana konsumen 
secara tiba-tiba merasa ingin membeli sesuatu barang yang tidak direncanakan sebelumnya, namun di dunia maya juga ditemukan adanya pembelian impulsif melalui perantara aplikasi belanja online.

Faktor yang mempengaruhi terjadinya pembelian impulsif menurut Prastia (2015) adalah gaya-hidup berbelanja, keterlibatan fashion, dan perilaku hedonik. Berbelanja merupakan hal yang menyenangkan dan pelanggan cenderung melakukan pembelian impulsif. Gaya hidup berbelanja mendorong seseorang mengalokasikan waktu dan uang untuk mendapatkan berbagai produk selama proses berbelanja. Gaya hidup berbelanja dapat dipengaruhi dari faktor - faktor menarik yang ditawarkan, seperti: promosi, diskon, harga murah, iklan, model terbaru dan lain - lain (Samuel, 2005; Rohman, 2009).

Kegiatan berbelanja seringkali menjadikan seseorang memiliki kecenderungan hedonisme. Hedonisme dipengaruhi oleh beberapa faktor yang salah satunya adalah motif hedonik. Motif hedonik adalah suatu hal yang dapat menggerakkan atau mendorong seseorang untuk memenuhi kebutuhannya pada kesenangan atau kenikmatan materi sebagai tujuan utamanya. Motif hedonik selama berbelanja itu sendiri tercipta karena adanya gairah seseorang dalam berbelanja yang dipengaruhi oleh sesuatu yang baru atau tren yang baru.

Menurut Kosyu, dkk (2014:3) alasan seseorang memiliki perilaku hedonik adalah karena banyaknya kebutuhan yang tidak dapat terpenuhi sebelumnya, kemudian setelah kebutuhan tersebut terpenuhi, muncul lagi kebutuhan yang baru dan terkadang kebutuhan tersebut lebih prioritas dari kebutuhan yang sebelumnya dan dengan adanya pemenuhan tersebut akan muncul kepuasan dan rasa senang yang dirasakan oleh seseorang tersebut.

Salah satu situs belanja yang ada di Indonesia adalah Shopee. Shopee merupakan aplikasi mobile commerce bebasis marketplace, Shopee merupakan wadah belanja online yang lebih fokus kepada platform mobile sehingga orang-orang lebih mudah mencari, berbelanja, dan berjualan langsung hanya melalui ponselnya saja. Aplikasi Shopee dilengkapi dengan fitur live chat, berbagi (social sharing) dan shopee live (penawaran produk secar lngsung mellui video live streaming) yang menjadikanya berbeda dengan perusahaan e-commerce lain. 
Hasil penelitian Snapcart terhadap 6.000 responden pada Januari 2018 menunjukan Shopee sebagai situs penjualan online yang paling banyak dikunjungi masyarakat Indonesia. Riset yang dilakukan iPrice (kerja sama dengan dua perusahaan analisis, yakni Similar Web dan App Annie), juga merilis laporan peta persaingan e-commerce di Indonesia tahun 2018. Pengguna aktif bulanan Shopee tercatat di urutan pertama dengan pengguna bulanan terbanyak pada aplikasi mobile, baik di AppStore maupun PlayStore. Tingkat kunjungan bulanan di web juga mengalami peningkatan terbesar dibanding dengan e-commerence lainnya, dengan jumlah kunjungan sebanyak 74.995.300 kunjungan.

Maka berdasarkan pada fenomena dan gejala tersebut penelitian ini bertujuan melihat pengaruh gaya hidup berbelanja dan perilaku hedonik terhadap pembelian impulsif pada konsumen Shopee. Rumusan masalah dalam penelitian ini sebagai berikut: Bagaimana tanggapan responden terhadap gaya hidup berbelanja? Bagaimana tanggapan responden terhadap perilaku hedonik? Bagaimana tanggapan responden terhadap pembelian impulsif? Apakah terdapat pengaruh gaya hidup berbelanja terhadap pembelian impulsif? Apakah terdapat pengaruh perilaku hedonik terhadap pembelian impulsif? Apakah gaya hidup berbelanja dan perilaku hedonik bersama-sama berpengaruh terhadap pembelian impulsif?

\section{LANDASAN TEORI}

\section{Gaya Hidup Berbelanja}

Gaya hidup berbelanja mengacu pada pola konsumsi yang mencerminkan pilihan seseorang tentang bagaimana cara menghabiskan waktu dan uang. Dalam arti ekonomi, gaya hidup berbelanja menunjukkan cara yang dipilih oleh seseorang untuk mengalokasikan pendapatan, baik dari segi alokasi dana untuk berbagai produk dan layanan, serta alternatif - alternatif tertentu dalam pembedaan kategori serupa (Japarinto dan Sugiharto, 2016). Cobb dan Hoyer (1986) mengungkapkan bahwa konsumen diminta untuk menunjukkan sejauh mana mereka sepakat atau tidak setuju dengan pernyataan yang berkaitan dengan gaya hidup berbelanja (misalnya: sikap terhadap merk nasional, pengaruh iklan, harga kesadaran). 


\section{Perilaku Hedonik}

Menurut Nguyen, dkk (2007) Perilaku belanja hedonik mengacu pada rekreasi, perasaan menyenangkan, keadaan intrinsik dan berorientasi pada stimulasi motivasi. Perilaku ini merupakan pengalaman konsumsi yang berhubungan dengan perasaan, fantasi, kesenangan, dan pancaindera, dimana pengalaman tersebut mempengaruhi emosi seseorang, sebagai suatu bentuk sikap yang muncul secara spontan dari dalam diri konsumen. Perilaku hedonik sudah disadari sebagai suatu motivasi pembelian dari dalam diri konsumen karena konsumen menyukainya. Di dorong keinginan untuk mencapai suatu bentuk kesenangan, kebebasan, khayalan, serta pelarian diri dari masalah. Semuel melihat perilaku hedonik mencerminkan instrumen yang menyajikan secara langsung manfaat dari suatu pengalaman dalam melakukan pembelanjaan, seperti: kesenangan dan hal-hal baru (Semuel, 2005). Jones berpendapat perilaku ini mencerminkan nilai yang ditemukan dalam belanja yang berhubungan dengan tugas dan pengalaman belanja konsumen (Jones,dkk 2006).

\section{Pembelian Impulsif}

Pemahaman tentang konsep pembelian impulsif (pembelian impulsif) dan pembelian tidak direncanakan (unplanned buying) oleh beberapa peneliti tidak dibedakan. Bayley dan Nancarrow (1998) tidak membedakan antara unplanned buying dengan pembelian impulsif, tetapi memberikan perhatian penting kepada periset pelanggan harus memfokuskan pada interaksi antara point-of-sale dengan pembeli yang sering diabaikan. Engel dan Blackwell (1994), mendefinisikan unplanned buying adalah suatu tindakan pembelian yang dibuat tanpa direncanakan sebelumnya atau keputusan pembelian dilakukan pada saat berada di dalam toko. Coob dan Hayer (1986) mengklasifikasikan suatu pembelian impulsif terjadi apabila tidak terdapat tujuan pembelian merek tertentu atau kategori produk tertentu pada saat masuk ke dalam toko. Beberapa peneliti pemasaran beranggapan bahwa impulse sinonim dengan unplanned ketika para psikolog dan ekonom memfokuskan pada aspek irasional atau pembeli impulsif murni (Bayley dan Nancarrow, 1998). 


\section{Penelitian Terdahulu}

Penelitian yang dilakukan oleh Darma (2014) menyimpulkan bahwa tidak terdapat pengaruh yang signifikan dari perilaku hedonik terhadap pembelian impulsif. Terdapat pengaruh yang signifikan dari perilaku hedonik terhadap positive emotion. Terdapat pengaruh yang signifikan dari perilaku hedonik terhadap gaya hidup berbelanja. Terdapat pengaruh yang signifikan dari positive emotion terhadap pembelian impulsif. Tidak terdapat pengaruh yang signifikan dari gaya hidup berbelanja terhadap pembelian impulsif dan terdapat pengaruh signifikan dari gaya hidup berbelanja terhadap positive emotion. Prastia (2015) menyatakan bahwa gaya hidup berbelanja, keterlibatan fashion, dan perilaku hedonik secara signifikan berpengaruh signifikan terhadap perilaku pembelian impulsif.

Japarianto dan Sugiharto (2016) menyatakan bahwa gaya hidup berbelanja berpengaruh signifikan terhadap pembelian impulsif pada masyarakat high income dan gaya hidup berbelanja memiliki pengaruh yang paling dominan diantara variabel lain yang ada terhadap pembelian impulsif pada masyarakat high income. Wells dkk (2012) melakukan penelitian tentang pembelian impulsif dapat dipengaruhi secara positif dan negatif oleh berbagai tingkat kualitas situs web. Jadi, sementara kualitas objektif dari situs web e-commerce penting, pembelian impulsif juga merupakan faktor penting untuk memahami bagaimana dan mengapa individu bereaksi secara impulsif terhadap berbagai tingkat kualitas situs web.

Penelitian yang dilakukan oleh Wunas (2015) menyatakan bahwa pembelian impulsif merupakan faktor penting bagi konsumen untuk memutuskan akan loyal pada suatu ritel atau tidak. Penelitian yang dilakukan oleh Rohman (2009) menyatakan bahwa perilaku hedonik konsumsi tidak mempengaruhi keputusan pembelian impulsif karena nilai hedonik konsumsi berhubungan dengan motivasi konsumen untuk mendapatkan kesenangan pada waktu berbelanja. Menurut Lumintang (2012) menyatakan bahwa gaya hidup berbelanja berpengaruh signifikan terhadap pembelian impulsif. Hasil penelitian menunjukan semakin tinggi gaya berbelanja seseorang maka tingkat pembelian impulsif pada media online juga akan semakin besar. 


\section{Kerangka Pikir}

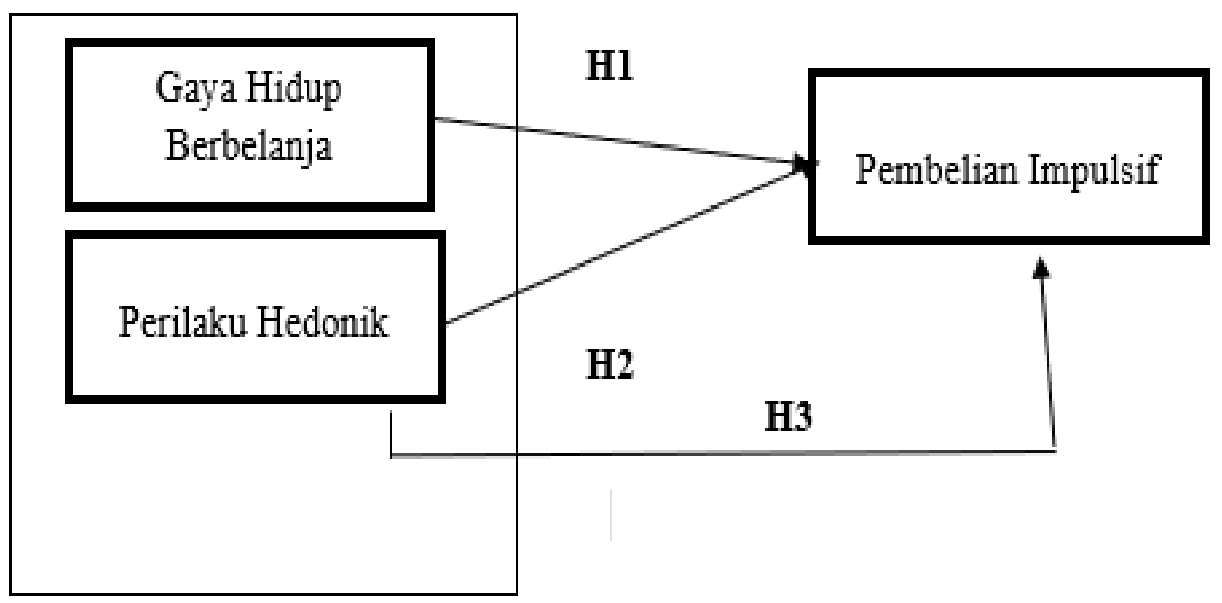

\section{Gambar 1. Kerangka Pikir Penelitian}

\section{Hipotesis}

H1: Terdapat pengaruh gaya hidup berbelanja terhadap pembelian impulsif.

$\mathrm{H} 2$ : Terdapat pengaruh perilaku hedonik terhadap pembelian impulsive

H3:Terdapat pengaruh gaya hidup berbelanja dan perilaku hedonik terhadap pembelian impulsif.

\section{METODE PENELITIAN}

Populasi yang akan diteliti dalam penelitian ini adalah mahasiswa konsumen online Shopee di UNIKA Soegijapranata Semarang yang melakukan pembelian minimal 3 kali dalam 3 bulan terakhir (bulan Mei - Juli 2019). Teknik purposive sampling adalah teknik pengambilan sampel berdasarkan pada kriteria tertentu. Dalam penelitian ini kriteria sampel yang digunakan adalah: mahasiswa dari lingkungan Universitas Katolik Soegijapranata Semarang; merupakan konsumen yang berbelanja di Shoope; dan minimal telah bertransaksi 3 kali dalam 3 bulan terakhir (Mei - Juli 2019)

Metode pengumpulan data pada penelitian ini yaitu dengan menggunakan kuesioner. Menurut Sugiyono (2010) kuesioner merupakan teknik pengumpulan data yang dilakukan dengan cara memberikan seperangkat pertanyaan atau pernyataan tertulis kepada responden untuk dijawabnya. Kuesioner dibuat dengan kategori multiple choice 
JEMAP: Jurnal Ekonomi, Manajemen, Akuntansi, dan Perpajakan

dengan menggunakan skala likert, dimana setiap butir pertanyaan dibagi menjadi 5 skala ukur yaitu sangat setuju (skor 5), setuju (skor 4), netral (skor 3), tidak setuju (skor 2), sangat tidak setuju (skor 1).

Penelitian ini menggunakan uji asumsi klasik yang terdiri dari uji normalitas, heterokedastisitas, multikolinearitas, dan autokorelasi serta uji analisi regresi berganda. Dengan persamaan sebgaai berikut: $\mathrm{Y}=\mathrm{a}+\beta 1 \mathrm{X} 1+\beta 2 \mathrm{X} 2+\mathrm{e}$

Keterangan $: \mathrm{Y}=$ Pembelian impulsif. $\mathrm{a}=$ Konstanta. $\mathrm{b} 1=$ Koefisien regresi .

$$
\mathrm{X} 1=\text { Gaya hidup berbelanja. } \mathrm{X} 2=\text { Perilaku hedonik. } \mathrm{e}=\text { eror }
$$

Uji $\mathrm{t}$ dilakukan dengan menggunakan signifikan tingkat $\alpha \quad 5 \%$. Kriteria penerimaan/penolakan hipotesis: Hipotesis diterima jika sig. $\leq \alpha$ dan Hipotesis ditolak jika sig. $>\alpha$. Uji F dilakukan untuk mengetahui pengaruh semua variabel independen yang terdapat di dalam model secara bersama-sama (simultan) terhadap variabel dependen. Uji F dalam penelitian ini digunakan untuk menguji signifikasi pengaruh gaya hidup berbelanja dan perilaku hedonik terhadap pembelian impulsif secara simultan. Kriteria pengambilan keputusan sebagai berikut $: \mathrm{H}_{0}$ ditolak dan Ha diterima, jika F hitung $\geq \mathrm{F}$ tabel. $\mathrm{H}_{0}$ diterima dan Ha ditolak, jika $\mathrm{F}$ hitung $\leq \mathrm{F}$ tabel

\section{HASIL ANALISIS DAN PEMBAHASAN}

\section{Hasil Uji Asumsi Klasik}

Berikut ini adalah tabel hasil pengujian normalitas:

Tabel 1. Hasil Pengujian Normalitas

\begin{tabular}{cc}
\hline & Unstandardized Residual \\
\hline Asymp. Sig. (2-tailed) & 0,061 \\
\hline
\end{tabular}

a. Test distribution is Normal.

b. Calculated from data

Sumber : Data Primer yang Diolah (2019) 
JEMAP: Jurnal Ekonomi, Manajemen, Akuntansi, dan Perpajakan

Dilihat dari tabel 1. menunjukan nilai Asymp. Sig. untuk unstandardized residual Komogorov - Smirnov pada penelitian ini adalah 0,061. Nili tersebut lebih besar daripada alpha $(0,05)$. Sehingga dapat dikatakan data pada penelitian ini telah terdistribusi secara normal.

Berikut ini adalah tabel yang menunjukan hasil pengujian multikolinearitas:

Tabel 2. Hasil Uji Multikolinearitas

\begin{tabular}{llll}
\hline \multirow{2}{*}{ Model } & \multicolumn{2}{c}{ Collinearity Statistics } \\
\cline { 2 - 4 } & & Tolerance & VIF \\
\hline \multirow{2}{*}{1} & Gaya Hidup erbelanja &, 934 & 1,071 \\
\cline { 2 - 4 } & Perilaku Hedonik &, 934 & 1,071 \\
\hline
\end{tabular}

a. Dependent Variable: PembelianImpulsif

Sumber : Data Primer yang Diolah (2019)

Dilihat dari tabel 2., dihaslkan bahwa nilai tolerance untuk gaya hidup bebelanja dan perilaku hedonik $>0,1$ dengan nilai $\mathrm{VIF}<10$, maka dapat disimpulkan bahwa tidak terjadi multikolinearitas antar variabel independen dalam model regresi.

Berikut ini adalah hasil uji heterokedastisitas:

Tabel 3. Hasil Uji Heteroskedastisitas

\begin{tabular}{lll} 
& \multicolumn{1}{c}{ Model } & Sig. \\
\hline \multirow{3}{*}{1} & (Constant) &, 866 \\
\cline { 2 - 3 } & Gaya Hidup Berbelanja &, 471 \\
\cline { 2 - 3 } & Perilaku Hedonik &, 530 \\
\hline
\end{tabular}

a. Dependent Variable: abs_res

Sumber : Data Primer yang Diolah (2019) 
JEMAP: Jurnal Ekonomi, Manajemen, Akuntansi, dan Perpajakan

Berdasarkan tabel 3, nilai signifikansi uji adalah 0,471 untuk variabel gaya hidup berbelanja dan sebesar 0,530 untuk variabel perilaku hedonik. Menunjukan bahwa dengan uji Glejser dimana variabel - variabel independen dalam menghitung nilai yang diestimasi diregresikan dengan nilai absolut dari unstandardized residual (ABS_RES) dan menghasilkan nilai signifikansi $>5 \%$ sehingga telah bebas dari heterokedastisitas, yang artinya nilai variance dari residual regresi tersebut adalah sama antara pengamatan satu dengan pengamatan lainnya.

\section{Analisis Regresi Linear Berganda}

Pada penelitian ini menggunakan analisis regresi linear berganda dengan hasil sebagai berikut:

Tabel 4. Analisis Regresi Linear Berganda

\begin{tabular}{|c|c|c|c|c|}
\hline & \multirow{2}{*}{ Model } & \multicolumn{2}{|c|}{ Unstandardized Coefficients } & \multirow{2}{*}{ Sig. } \\
\hline & & B & Std. Error & \\
\hline \multirow{3}{*}{1} & (Constant) & 1,289 & 1,810 & ,478 \\
\hline & GayaHidupBerbelanja &, 134 &, 042 & ,002 \\
\hline & PerilakuHedonik & ,454 & 055 &, 000 \\
\hline
\end{tabular}

a. Dependent Variable: PembelianImpulsif

Sumber : Data Primer yang Diolah (2019)

Persamaan regresi: $\mathrm{Y}=1,289+0,134 \mathrm{X}_{1}+0,454 \mathrm{X}_{2}+\mathrm{e}$

Dimana: $\mathrm{Y}=$ Pembelian impulsif. $\mathrm{X}_{1}=$ Gaya hidup berbelanja

$\mathrm{X}_{2}=$ Perilaku hedonik. $\mathrm{e}=$ eror.

Nilai koefisien gaya hidup berbelanja untuk variabel $\mathrm{X}_{1}$ sebesar 0,134 dan bertanda positif, ini menunjukkan bahwa gaya hidup berbelanja mempunyai pengaruh yang searah dengan pembelian impulsif. Hal ini memiliki arti bahwa semakin seseorang memiliki gaya hidup dalam berbelanja maka pembelian yang dilakukan juga akan semakin impulsif. Nilai koefisien perilaku hedonik untuk variabel $\mathrm{X}_{2}$ sebesar 0,454 dan bertanda positif, ini menunjukkan bahwa perilaku hedonik mempunyai pengaruh yang 
JEMAP: Jurnal Ekonomi, Manajemen, Akuntansi, dan Perpajakan

searah dengan pembelian impulsif. Hal ini memiliki arti bahwa semakin hedonik perilaku sesorang ketika berbelanja maka pembelian yang dilakukan juga akan semakin impulsif.

\section{Koefisien Determinasi $\left(\mathbf{R}^{2}\right)$}

Tabel 5. Hasil Uji Koefisien Determinasi $\left(\boldsymbol{R}^{2}\right)$

\begin{tabular}{cccc}
\hline Model & $\mathrm{R}$ & R Square & Adjusted R Square \\
\hline 1 &, $707^{\mathrm{a}}$ &, 501 &, 490 \\
\hline
\end{tabular}

a. Predictors: (Constant), PerilakuHedonik, GayaHidupBerbelanja

b. Dependent Variable: PembelianImpulsif

Sumber : Data Primer yang Diolah (2019)

Berdasarkan pada tabel 5. diketahui nilai Adjusted $R^{2}$ sebesar 0,490 artinya variabel independen (gaya hidup berbelanja dan perilaku hedonik) mempengaruhi variabel dependen (pembelian impulsif) sebesar $49 \%$ dan sisanya sebesar 51\% dipengaruhi oleh variabel lainnya.

Tabel 6. Hasil Uji t

\begin{tabular}{lllll}
\hline \multirow{2}{*}{ Model } & \multicolumn{3}{c}{ Unstandardized } & \\
\cline { 2 - 4 } & & \multicolumn{2}{c}{ Coefficients } & \multirow{2}{*}{ Sig. } \\
\cline { 2 - 4 } 1 & (Constant) & 1,289 & Std. Error & \\
\cline { 2 - 4 } & GayaHidupBerbelanja &, 134 &, 042 &, 478 \\
\cline { 2 - 4 } & PerilakuHedonik &, 454 &, 055 &, 000 \\
\hline
\end{tabular}

a. Dependent Variable: Pembelian Impulsif

Berdasarkan tabel 6. diketahui bahwa nilai koefisien regresi $(\beta 1)$ adalah $+0,134$ dan nilai signifikansi untuk gaya hidup berbelanja sebesar 0,002 $<0,05$ yang menunjukan hipotesis pertama diterima, yang mengindikasikan bahwa gaya hidup berbelanja berpengaruh positif terhadap pembelian impulsif. Hal ini berarti semakin meningkat gaya hidup berbelanja maka semakin tinggi pula kemungkinan terjadinya pembelian impulsif. Nilai koefisien regresi $(\beta 2)$ adalah $+0,454$ dan nilai signifikansi untuk perilaku hedonik sebesar $0,000<0,05$ yang menunjukan hipotesis kedua diterima, yang mengindikasikan bahwa perilaku hedonik berpengaruh positif terhadap pembelian impulsif. Hal ini berarti 
semakin meningkat perilaku hedonik maka semakin tinggi pula kemungkinan terjadinya pembelian impulsif.

Tabel 7. Hasil Uji F

\begin{tabular}{lll}
\hline & \multicolumn{1}{c}{ Model } & Sig. \\
\hline \multirow{3}{*}{1} & Regression &, $000^{\mathrm{b}}$ \\
\cline { 2 - 3 } & Residual & \\
\cline { 2 - 3 } & Total & \\
\hline
\end{tabular}

a. Dependent Variable: PembelianImpulsif

b. Predictors: (Constant), PerilakuHedonik, GayaHidupBerbelanja

Sumber : Data Primer yang Diolah (2019)

Berdasarkan pada tabel 7 dieroleh hasil nilai signifikansi sebesar $0,000<0,05$ sehingga dengan demikian dikatakan model fit dan variabel gaya hidup berbelanja dan perilaku hedonik secara bersama - sama (simultan) dapat digunakan untuk memprediksi variabel pembelian impulsif. Hasil ini menunjukan bahwa hipotesis ketiga diterima.

\section{PEMBAHASAN}

\section{Pengaruh Gaya Hidup Berbelanja Terhadap Pembelian Impulsif}

Gaya hidup berbelanja merupakan cara seseorang untuk mengalokasikan waktu dan uang yang dimiliki untuk melakukan kegiatan berbelanja. Gaya hidup berbelanja juga ditentukan oleh beberapa faktor antara lain sikap terhadap merek, pengaruh iklan dan kepribadian. Gaya hidup berbelanja dalam penelitian ini menunjukan bahwa pelanggan Shopee akan melakukan kegiatan berbelanja suatu produk di Shopee karena melihat iklan yang ditawarkan Shopee. Keterertarikan para pelanggan Shopee dalam melakukan belanja produk di Shopee dikarenakan adanya model yang terbaru dan merek yang terkenal dengan jumlah lebih dari satu merek yang dibeli. Pelanggan Shopee yang berbelanja produk di Shopee akan mencari produk dengan kualitas terbaik. Pelanggan Shopee akan membandingkan produk dari berbagai macam penjual yang ada di Shopee. Pelanggan Shopee akan membeli produk lebih banyak dibandingkan biasanya ketika ada promosi yang sedang ditawarkan. Membandingkan harga secara hati - hati dan 
mempertimbangkan merek produk saat membeli produk di Shopee juga menjadi tolak ukur gaya hidup berbelanja.

Adanya gaya hidup berbelanja seperti yang dijelaskan di atas akan semakin meningkatkan kemungkinan terjadinya pembelian secara impulsif, dimana seseorang membeli suatu produk tanpa direncanakan terlebih dahulu dan tanpa ada pertimbangan secara mendalam. Dengan demikian dapat dikatakan terdapat pengaruh positif antara gaya hidup berbelanja terhadap pembelian impulsif. Hasil penelitian ini konsisten dengan penelitian yang dilakukan oleh Darma (2014), Prastia (2015) serta Japarianto dan Sugiharto (2016) yang menyatakan bahwa gaya hidup berbelanja berpengaruh signifikan terhadap pembelian impulsif.

\section{Pengaruh Perilaku Hedonik Terhadap Pembelian Impulsif}

Perilaku hedonik merupakan suatu motivasi pembelian dari dalam diri konsumen karena konsumen menyukainnya. Di dorong keinginan untuk mencapai suatu bentuk kesenangan, kebebasan, khayalan, serta pelarian diri dari masalah. Perilaku hedonik dalam penelitian ini menunjukan bahwa pelanggan Shopee berbelanja pakaian branded di Shopee pada saat sedang trending. Pelanggan Shopee berbelanja tas dan aksesoris dengan merek yang terkenal di Shopee. Pelanggan Shopee berbelanja handphone dengan fasilitas layanan yang paling terbaru. Pelanggan Shopee memiliki kepuasan tersendiri ketika berbelanja untuk orang lain di Shopee. Pelanggan Shopee berbelanja produk dalam jumlah yang besar khususnya ketika sedang ada promo atau diskon menarik yang ditawarkan.

Adanya perilaku hedonik seperti yang dijelaskan di atas akan semakin meningkatkan kemungkinan terjadinya pembelian secara impulsif, dimana seseorang membeli suatu produk tanpa direncanakan terlebih dahulu dan tanpa ada pertimbangan secara mendalam. Dengan demikian dapat dikatakan terdapat pengaruh positif antara perilaku hedonik terhadap pembelian impulsif. Hasil penelitian ini konsisten dengan penelitian yang dilakukan oleh Prastia (2015) serta Nguyen dkk (2007) yang menyatakan bahwa perilaku hedonik berpengaruh signifikan terhadap pembelian impulsif. 


\section{Pengaruh Gaya Hidup Berbelanja dan Perilaku Hedonik Terhadap Pembelian Impulsif}

Dengan adanya gaya hidup berbelanja dan perilaku hedonik dalam suatu kegiatan berbelanja, secara bersama - sama dapat memungkinkan terjadinya pembelian impulsif pada seseorang. Dorongan ini dapat memunculkan kondisi impulsif selama transaksi berbelanja, dimana pada saat membeli suatu produk di Shopee sering dilakukan tanpa perencanaan terlebih dahulu. Pembelian dilakukan tanpa adanya pertimbangan yang mendalam mengenai produk yang dibeli. Pembelian juga sering dilakukan secara terburu - buru dan menuruti keinginan emosional sesaat.

Gaya hidup berbelanja dan perilaku hedonik secara bersama - sama dapat meningkatkan kemungkinan terjadinya pembelian secara impulsif, dimana seseorang membeli suatu produk tanpa direncanakan terlebih dahulu dan tanpa ada pertimbangan secara mendalam. Dengan demikian dapat dikatakan terdapat pengaruh positif antara gaya hidup berbelanja dan perilaku hedonik terhadap pembelian impulsif. Berdasarkan pada hasil pengujian hipotesis ketiga diketahui bahwa gaya hidup berbelanja dan perilaku hedonik berengaruh positif terhadap pembelian impulsif. Artinya hipotesis ketiga pada penelitian ini terdukung secara empiris. Hasil penelitian ini konsisten dengan penelitian yang dilakukan oleh Tirmizi dkk (2009) serta Gültekin dan Özer (2012) yang menyatakan ada pengaruh gaya hidup berbelanja dan perilaku hedonik terhadap pembelian impulsif.

\section{PENUTUP}

Berdasarkan hasil pengujian diperoleh kesimpulan sebagai berikut tanggapan responden terhadap gaya hidup berbelanja adalah setuju, hal ini diketahui dari rata-rata jawaban responden untuk variabel gaya hidup berbelanja sebesar 4,18. Tanggapan responden terhadap perilaku hedonik adalah setuju, hal ini diketahui dari rata-rata jawaban responden untuk variabel perilaku hedonik sebesar 3,87. Tanggapan responden terhadap pembelian impulsif adalah setuju, hal ini diketahui dari rata-rata jawaban responden untuk variabel pembelian impulsif sebesar 3,92. 
Hasil pengujian variabel gaya hidup berbelanja menunjukan tingkat signifikansi sebesar 0,002 <0,05. Dengan demikian dapat disimpulkan bahwa gaya hidup berbelanja berpengaruh positif dan signifikan terhadap pembelian impulsif. Artinya H1 dalam penelitian ini diterima. Hasil pengujian variabel perilaku hedonik menunjukan tingkat signifikansi sebesar $0,000<0,05$. Dengan demikian dapat disimpulkan bahwa perilaku hedonik berpengaruh positif dan signifikan terhadap pembelian impulsif. Artinya H2 dalam penelitian ini diterima. Hasil pengujian variabel gaya hidup berbelanja dan perilaku hedonik secara bersama - sama menunjukan tingkat signifikansi sebesar 0,000 $<0,05$. Dengan demikian dapat disimpulkan bahwa gaya hidup berbelanja dan perilaku hedonik secara bersama - sama berpengaruh positif dan signifikan terhadap pembelian impulsif. Artinya $\mathrm{H} 3$ dalam penelitian ini diterima.

Berdasarkan hasil penelitian terdapat beberapa saran untuk penelitian di masa yang akan datang, yaitu sebagai berikut: Dasar pengembangan strategi bisnis Shopee semakin memfokuskan strategi dalam mengarahkan gaya hidup berbelanja para konsumennya dengan cara terus mengupdate produk - produk yang dijual Shopee dengan model model terbaru, menyediakan pilihan produk dengan varian merek yang beragam, serta mengedepankan produk yang memiliki kualitas terbaik. Selain itu Shopee juga dapat mengembangkan strategi melalui cara menstimulasi perilaku hedonik konsumenya dengan memberikan promo - promo beragam seperti diskon hari kemerdekaan (diskon dengan potongan sebesar umur Indonesia), diskon setiap bulan seperti tanggal 10 bulan 10, tanggal 11 bulan 11, tanggal 10 bulan 12 dengan promo gratis ongkir.

Penelitian selanjutnya disarankan untuk menambahkan variabel independen yang mempengaruhi pembelian impultif, misalnya positive emotion dan kualitas situs website. Karena dengan adanya semakin tinggi emosi positif dan kualitas situs website berarti konsumen semakin tertarik terhadap situs wesbite tertentu yang akan berdampak pada pembelian impultif. 
JEMAP: Jurnal Ekonomi, Manajemen, Akuntansi, dan Perpajakan

\section{DAFTAR PUSTAKA}

Bayley, G. \& Nancarrow, C. (1998). Impulse Purchasing: A Qualitative Exploration of The Phenolmenon. Qualitative Market Research: An Inter-natinal Journal, 1(2), pp. 99-114.

Cobb J.C. \& Hoyer W.D. (1986). Planned Versus Impulse Purchase Behaviour. Journal of Retailing, 62(4), pp. 384-409.

Darma, Lizamary Angelina dan Japarianto, Edwin (2014). Analisa Pengaruh Hedonic Shopping Value Terhadap Pembelian impulsif Dengan Gaya hidup berbelanja Dan Positive Emotion Sebagai Variabel Intervening Pada Mall Ciputra World Surabaya. JURNAL MANAJEMEN PEMASARAN, Vol. 8, No. 2, Oktober 2014.

Engel, James F., Blackwell, R.D. \& Budiyanto, FX. (1994). Perilaku Konsumen, Jilid 1 (Edisi ke-enam), Jakarta: Binarupa Aksara.

Gültekin, Beyza dan Leyla Özer (2012). The Influence of Hedonic Motives and Browsing On Pembelian impulsif. Journal of Economics and Behavioral Studies, Vol.4 (3): pp. 180-189.

Japarianto, Edwin dan Sugiharto, Sugiono (2016). Pengaruh Shopping Life Style Dan Fashion Involment Terhadap Impulse Buying Behaviour Masyarakat High Income Surabaya. JURNAL MANAJEMEN PEMASARAN, VOL. 6, NO. 1.

Kosyu, Dayang Asning dan Hidayat, Kadarisman dan Abdullah, Yusri (2014). Pengaruh Hedonic Shopping Motives Terhadap Gaya Hidup Berbelanja Dan Pembelian Impulsif (Survei Pada Pelanggan Outlet Stradivarius Di Galaxy Mall Surabaya). Jurnal Administrasi Bisnis, 14(2) 17.

Lumintang, F. (2012). Pengaruh Hedonic Motives Terhadap Impulse Buying Melalui Browsing dan Gaya Hidup Berbelanja pada Online Shop. Jurnal Wima, 1(6).

Nguyen, T. T. Dkk. (2007). Hedonic Shopping Motivations, Supermarket Atributes, and Shopper Loyalty in Transitional Markets, Asia Pacific Journal of Marketing and Logistics, Vol. 19, No. 3, pp. 227-239. 
JEMAP: Jurnal Ekonomi, Manajemen, Akuntansi, dan Perpajakan

Prastia, Fita Eka. (2015). Pengaruh Shopping Lifestyle, Fashion Involment dan Hedonic Shopping Value Terhadap Impulse Buying Behaviour Pelanggan Toko Elizabeth Surabaya.

Rohman, Fatchur (2009). Peran Nilai Hedonik Konsumsi dan Reaksi Impulsif sebagai Mediasi Pengaruh Faktor Situasional terhadap Keputusan Pembelian Impulsif di Butik Kota Malang. Jurnal Aplikasi Manajemen. Vol. 7 (2): hlm. 251-261.

Semuel, H. (2005). Respons Lingkungan Berbelanja Sebagai Stimulus Pembelian Tidak Terencana pada Toko Serba Ada (Toserba), Jurnal Manajemen \& Kewirausahaan, vol. 7, no. 2, September: pp 152-170.

Sugiyono (2010). Metode Penelitian Bisnis. Bandung: CV Alfabeta

Tirmizi, A. M., Rehman, Ur, Kashif dan Saif. M. Iqbal. (2009). An Empirical Study Of Consumer Impulse Buying Behavior In Local Markets, European Journal of Scientific Research, Vol. 28, no: 4, pp: 522-532.

Wells, J. D., Parboteeah, D. V., \& Valacich, J. S. (2011). Online Impulse Buying : Understanding The Interplay between Consumer Impulsiveness and Website Quality. Journal of the Association of Information Systems, 12(1), 32-56.

Wunas, R. P. (2012). Pengaruh Advertising Attitude Terhadap Shopping Loyalty Melalui Pembelian Impulsif Pada Carrefour Golden City Mall Mayjen 